\title{
Energy and Environmental Performance of Bioethanol from Different Lignocelluloses
}

\author{
Lin Luo, Ester van der Voet, and Gjalt Huppes \\ Institute of Environmental Sciences (CML), Leiden University, P.O. Box 9518, 2300 RA Leiden, The Netherlands \\ Correspondence should be addressed to Lin Luo, luo@cml.leidenuniv.nl
}

Received 9 November 2009; Accepted 6 March 2010

Academic Editor: Ravichandra Potumarthi

Copyright () 2010 Lin Luo et al. This is an open access article distributed under the Creative Commons Attribution License, which permits unrestricted use, distribution, and reproduction in any medium, provided the original work is properly cited.

Climate change and the wish to reduce the dependence on oil are the incentives for the development of alternative energy sources. The use of lignocellulosic biomass together with cellulosic processing technology provides opportunities to produce fuel ethanol with less competition with food and nature. Many studies on energy analysis and life cycle assessment of second-generation bioethanol have been conducted. However, due to the different methodology used and different system boundary definition, it is difficult to compare their results. To permit a direct comparison of fuel ethanol from different lignocelluloses in terms of energy use and environmental impact, seven studies conducted in our group were summarized in this paper, where the same technologies were used to convert biomass to ethanol, the same system boundaries were defined, and the same allocation procedures were followed. A complete set of environmental impacts ranging from global warming potential to toxicity aspects is used. The results provide an overview on the energy efficiency and environmental performance of using fuel ethanol derived from different feedstocks in comparison with gasoline.

\section{Introduction}

Climate change and the wish to reduce the dependence on oil are the incentives for the development of alternative energy sources. In view of the carbon dioxide reduction target agreed upon in the Kyoto protocol, a shift from fossil fuels to renewable resources is ongoing, also to secure the long-term energy supply at both national and international level. The European Commission demonstrated in 2007 that a $20 \%$ target for the overall share of energy from renewable sources and a 10\% target for energy from renewable sources in transport would be appropriate and achievable objectives [1], though both targets have become subject of dispute since then. In the near term, liquid biofuels will still largely contribute to the target in transport sector due to the limited available technologies for fuels from other renewable sources. Especially bioethanol with its biorenewable nature, optimized production technology, and potential of greenhouse gas (GHG) mitigation already proved itself as an attractive alternative fuel.

Most of the current practice only concerns first-generation ethanol from conventional crops like corn, wheat, sorghum, potato, sugarcane, sugar beet, and so forth. Criticism is expressed on the first-generation bioethanol with regard to land use requirement and competition with food and nature. These issues have become the driving forces for the technology innovation towards second-generation ethanol from lignocellulosic feedstocks, both as agricultural coproducts and wastes and dedicated crops. EC Directive 2009 addressed the importance of commercializing secondgeneration biofuels [2]. The United States, as one of the leading nations in promoting biofuels, proposed that cellulosic ethanol must achieve $44 \%$ of the total biofuel production by 2020 [3].

With the development of the cellulosic technology being able to convert agricultural coproducts of often lower value to ethanol, two major questions are raised when comparing second-generation bioethanol to fossil fuel and first-generation bioethanol. (1) Is second-generation ethanol a better option for energy conservation? (2) What are the environmental benefits of second-generation ethanol? In order to answer the first question efforts were exerted on energy analysis of ethanol from corn stover $[4,5]$, switchgrass [6-9], and woodchip [7, 10]. Most of these studies yield 
a positive net energy value (NEV), which indicates that lignocelluloses are more favourable feedstocks than dedicated crops, that is, corn grain. However, Pimentel and Patzek [7] exceptionally reported negative NEV from switchgrassand wood-ethanol systems concluding that cellulosic ethanol processes are more energy intensive than ethanol from corn grain. With respect to the second question many life cycle assessment (LCA) studies were conducted on ethanol from lignocelluloses such as corn stover [11-15], Switchgrass [9, 11], Miscanthus and willow [16], sugarcane bagasse [17, 18], cereal straw [19], woodchip and wood wastes [20-22], flax shives [23], and hemp hurds [24]. All these studies, to different extent, show environmental benefits especially in terms of reduced fossil resource depletion and GHG emissions.

However, these studies on both energy analysis and LCA of second-generation bioethanol raise a number of questions. First of all, there is insufficient consistency regarding the definition of system boundaries, with different choices made without explicit arguments. For instance, an ethanol refining system does not include the environmental impact from the production of cellulase enzyme for degrading cellulosic feedstocks [25], leaving out a major energy requiring process. Secondly, in different studies allocation methods are different and not systematic and mostly are unclearly stated. A high sensitivity to the allocation method has been reported for LCA results when evaluating carbon intensity and fossil energy consumption for bioethanol pathways $[12,20,26$, 27]. The differences and ambiguities in the definition of system boundaries and allocation methodology made most of the studies incomparable.

To allow for a direct and meaningful comparison of different analysis, Farrell et al. [6] aligned methods and assumptions for six selected studies $[7,8,28-30]$ and removed differences in the underlying data. Their focus, however, is mostly on corn-based ethanol. They indicate that calculations of NEV are highly sensitive to assumptions about both system boundaries and key parameter values and, as to content. They conclude that large-scale use of fuel ethanol certainly requires more sustainable practices in agriculture and advanced technologies, shifting from corn based to cellulosic ethanol production.

In order to have an overview of the energy intensity and environmental performance of bioethanol production from different lignocellulosic feedstocks, we have conducted five LCA studies at CML $[12,18,23,24,31]$ and two studies on energy analysis [5, 32] of bioethanol from lignocelluloses, in all of which the same technologies were used to convert cellulose and hemicellulose to ethanol and to generate heat and power from lignin and wastes, the same system boundaries were defined, and the same allocation procedures were followed. In all LCA studies a comprehensive set of environmental impacts is used, ranging from abiotic depletion and GHG emissions to acidification and toxicity aspects. The present study summarizes and compares the results obtained from these five LCA studies and the two energy analyses, also in comparison with other studies.

\section{Life Cycle Assessment (LCA)}

2.1. Methodology. All five case studies compared in the present study focus on LCA of fuel ethanol from lignocellulosic feedstocks, with application of different allocation methods and/or scenario analysis. In all studies advanced cellulosic processing technology is assumed to convert biomass to ethanol, the system boundaries are identical, and the same allocation procedure is applied. Therefore they are well comparable. The feedstocks in these studies are summarized as follows:

(1) corn stover [12],

(2) sugarcane and bagasse [18],

(3) switchgrass [31],

(4) flax shives [23],

(5) hemp hurds [24].

In this section the methodologies used in all five studies are described. It is worth noting that study (2) presents a comparative LCA of ethanol production from solely sugar (current practice) and sugar plus bagasse (future case). As combining sugar and bagasse as feedstock for ethanol production is proposed to be a common practice in Brazil in the future, we did not perform an LCA on ethanol derived solely from bagasse. Thus the future case presented in study (2) is used to compare with other four studies, even though the feedstock includes not only the lignocellulose (bagasse) but also sugar.

2.1.1. Functional Unit and Alternatives. The functional unit in all studies is defined as power to wheels for one kilometre driving of a midsize flexible fuelled vehicle (FFV), which means that engine modification can be left out of account. Four fuel alternatives are considered: (1) conventional gasoline, (2) a blend of $90 \%$ gasoline with $10 \%$ ethanol by volume (termed E10), (3) a blend of 15\% gasoline with $85 \%$ ethanol by volume (termed E85), and (4) pure ethanol. In practice pure ethanol is not used as transport fuel; hence it is only a hypothetical case here for easy comparison with gasoline.

2.1.2. System Boundaries. The systems defined in all five studies are based on the "cradle-to-grave" approach, which includes crude oil extraction and refinery, with all transport required, and agriculture production of lignocellulosic biomass, harvest and transport of biomass to ethanol refinery, production of ethanol and its coproducts, blend and transport all fuels to regional storages, and the final use phase of fuels in vehicle driving. The production and transport of chemicals used in all processes are also taken into account. Moreover, emissions from capital goods production and waste management are included. However, emissions and wastes associated with the production and disposal of the FFV are outside the system boundaries.

In all five studies different coproducts are produced from either agricultural production or ethanol refinery, as listed in Table 1. In fact, in study (1), (2), (4), and (5) electricity is also cogenerated from the ethanol refinery; however, it is 


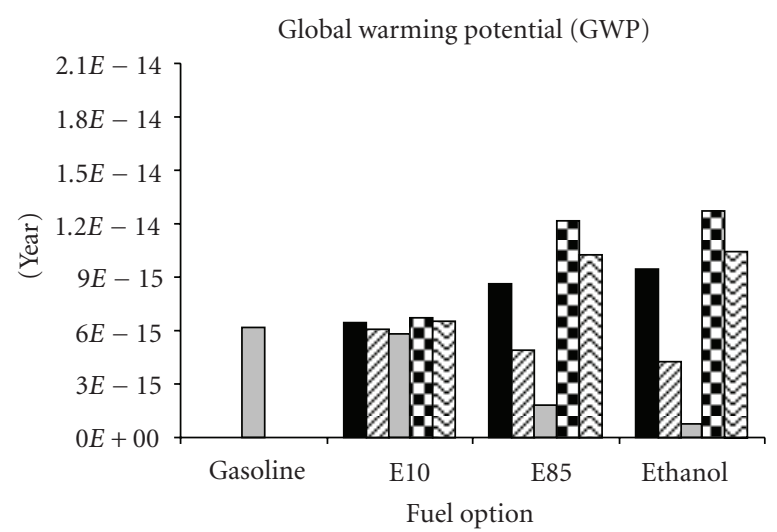

- Stover-ethanol

[. Sugarcane-ethanol

$\square$ Switchgrass-ethanol

(a)

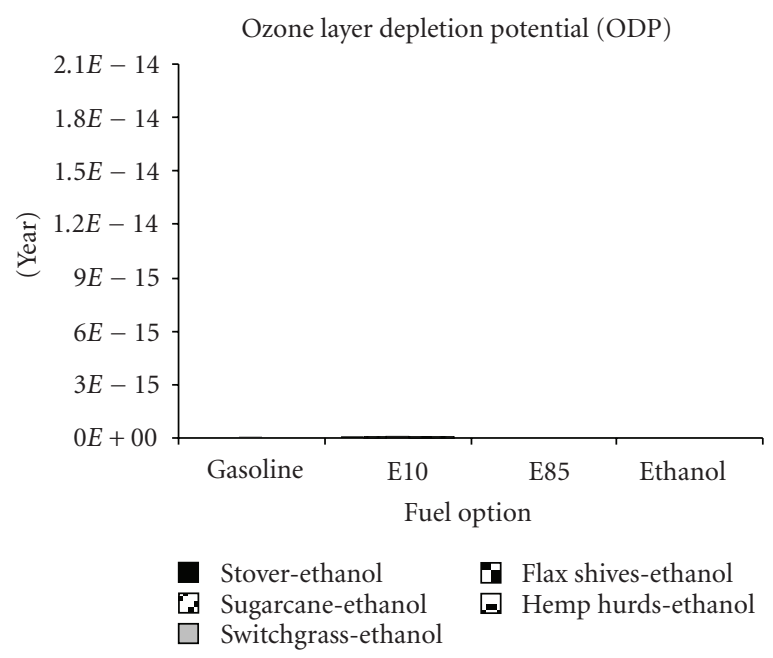

(c)

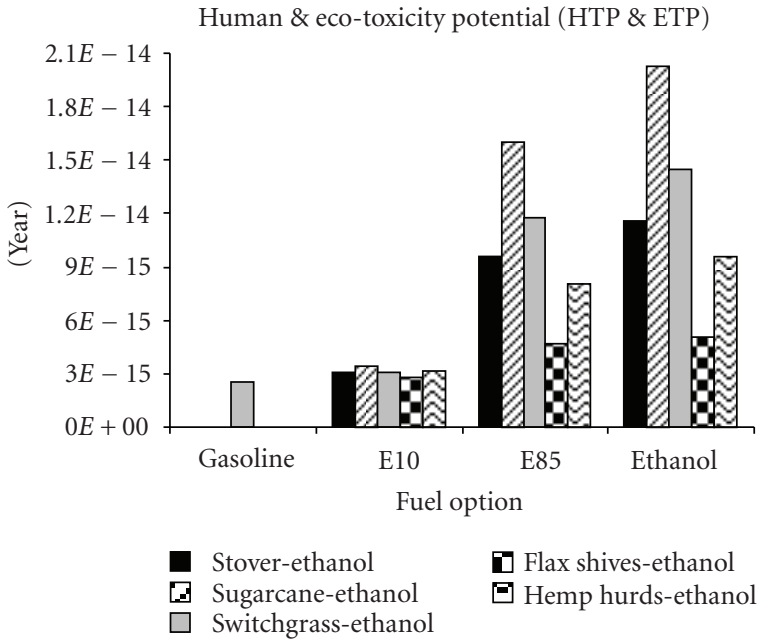

(e)

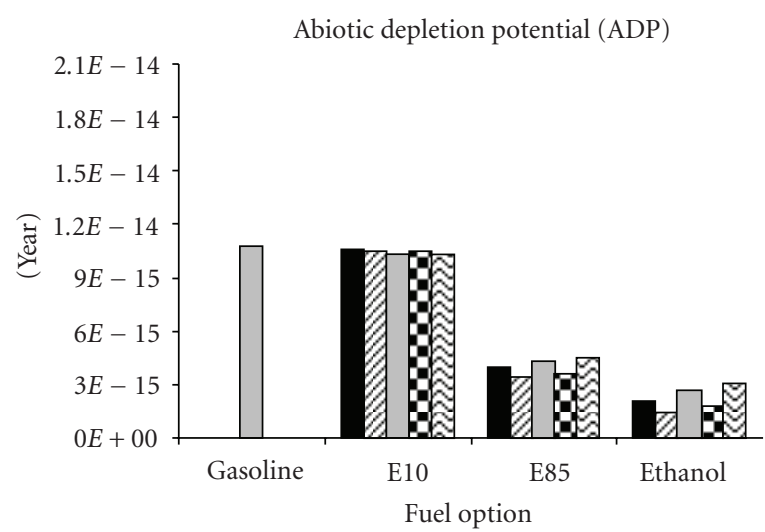

Stover-ethanol

¿ Flax shives-ethanol

Sugarcane-ethanol

Switchgrass-ethanol

ت Hemp hurds-ethanol

(b)

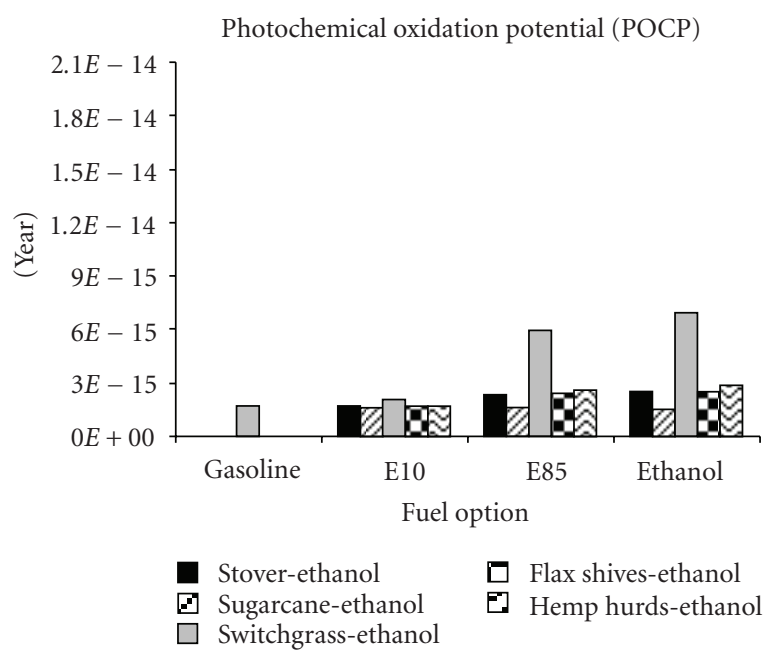

(d)

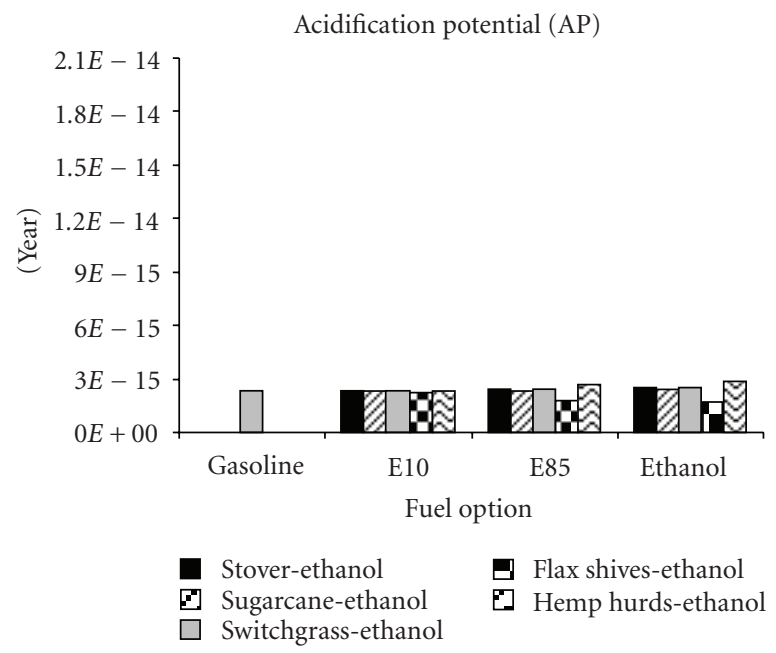

(f) 


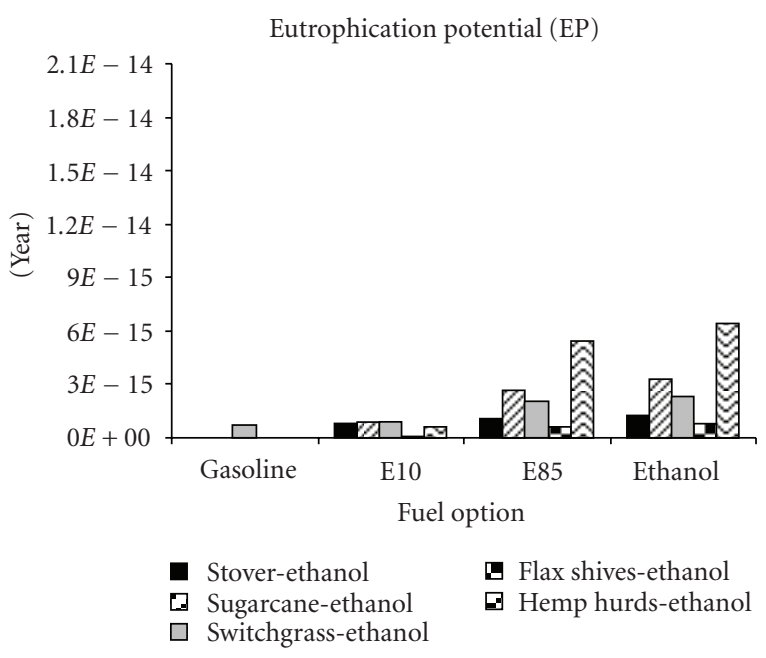

(g)

FIGURE 1: Overall comparison of environmental impact of all fuel options in all studies.

TABLE 1: Product and coproducts from agriculture and ethanol refinery.

\begin{tabular}{|c|c|c|c|c|}
\hline \multirow{3}{*}{ Study } & \multicolumn{4}{|c|}{ Products } \\
\hline & \multicolumn{2}{|c|}{ Agriculture } & \multicolumn{2}{|c|}{ Ethanol refinery } \\
\hline & Product & Coproducts & Product & Coproducts \\
\hline (1) Luo et al. [12] & Corn & Stover & Ethanol & - \\
\hline (2) Luo et al. [18] & Sugarcane & - & Ethanol & Sugar \\
\hline (3) Bai et al. [31] & Switchgrass & - & Ethanol & Electricity \\
\hline (4) González García et al. [23] & Shives & Fibres \& linseed & Ethanol & - \\
\hline (5) González García et al. [24] & Hurds & Fibres \& dust & Ethanol & - \\
\hline
\end{tabular}

fully utilized by the refinery and no surplus can be considered as co-product. In study (2) extra electricity needs to be purchased from local grid due to the insufficiency of the cogenerated electricity inside the refinery.

2.1.3. Data Sources and Software. Life cycle inventory (LCI) data used in all studies are obtained from different sources, as summarized in Table 2. The completeness of data may differ between sources; therefore, the Ecoinvent database from Swiss Centre of Life Cycle Inventories [33] is used as a standard whenever possible, as this source has long learning experience and involves a very broad range of processes (around 4,000). Software package Chain Management by Life Cycle Assessment (CMLCA) is used for the analysis [34].

2.1.4. Allocation Method. The allocation procedure in multiproduct processes has been always one of the most critical issues in LCA. The ISO 14040 and 14044 [51, 52] recommend a stepwise procedure for allocation. First of all, allocation should be avoided whenever possible through subdivision of certain processes or by expanding system boundaries so as to include the additional functions related to them. If allocation cannot be avoided, methods reflecting underlying physical relationships shall be applied, of how process inputs and outputs change due to a quantitative change in products and functions delivered. This is often filled in as allocation based on mass or energy content of the coproducts. To the extent that physical relations cannot be established, other relevant variables like economic values of the coproducts can be used to allocate. This last option is similar to the cost allocation methods used in managerial accounting $[53,54]$.

In all five studies, one allocation method is applied, followed by a sensitivity analysis when two or more allocation methods can be applied. In some studies methods based on mass or energy content cannot be applied systematically. For instance, in the case of electricity as a co-product in ethanol refinery, mass allocation is not applicable; in the case of sugar as a co-product, energy content allocation cannot be used. Therefore, in the present study, in order to permit a fair comparison, economic allocation, which is used in all five studies, is applied. In no case the more general ISO requirements on physical allocation have been used or met. The multiproduct processes in these studies are given as follows:

(1) corn agriculture, where corn and stover are produced;

(2) ethanol production from sugarcane and bagasse, where ethanol and sugar are produced;

(3) ethanol production from switchgrass, where ethanol and electricity are produced; 
TABle 2: Data sources for the life cycle inventories of the five studies.

\begin{tabular}{ll}
\hline Subsystem & Data source \\
\hline Corn agriculture & U.S. Life-Cycle Inventory Database [35] \\
Sugarcane agriculture & Macedo et al. [36] \\
Switchgrass agriculture & Bullard and Metcalfe [37]; Nemecek and Kägi [38] \\
Flax agriculture & Nemecek et al. [39], Hauschild [40], Audsley et al. [41], Arrouays et al. [42], EMEP/CORINAIR \\
& [43] \\
Hemp agriculture & [43] \\
Biomass transport & Spielmann et al. [39], Hauschild [40], Audsley et al. [41], Arrouays et al. [42], EMEP/CORINAIR \\
Stover-ethanol production & Aden et al. [45] \\
Sugarcane-ethanol production & Efe et al. [46] \\
Switchgrass-ethanol production & Guerra Miguez et al. [47] \\
Flax shives-ethanol production & Aden et al. [45] \\
Hemp hurds-ethanol production & Aden et al. [45] \\
Ethanol transport & Spielmann et al. [44] \\
Gasoline production \& transport & Swiss Centre of Life Cycle Inventories [33] \\
Emissions from capital goods & EIPRO Database [48] \\
production & Kelly et al. [49], Reading et al. [50] \\
Emissions from vehicle driving & Swiss Centre of Life Cycle Inventories [33] \\
Background processes &
\end{tabular}

Table 3: Partitioning factors for economic allocation in all five studies.

\begin{tabular}{lcc}
\hline Study & Multiproducts & Partitioning factor \\
\hline (1) Luo et al. [12] & Stover/corn & $0.118 / 0.882$ \\
(2) Luo et al. [18] & Ethanol/sugar & $0.837 / 0.163$ \\
(3) Bai et al. [31] & Ethanol/electricity & $0.894 / 0.106$ \\
(4) González & Shives/fibers/linseed & $0.042 / 0.911 / 0.047$ \\
$\quad$ García et al. [23] & & \\
(5) González & Hurds/fibers/dust & $0.122 / 0.863 / 0.015$ \\
$\quad$ García et al. [24] & & \\
\hline
\end{tabular}

(4) flax agriculture, where flax fibres, shives, and linseed are produced;

(5) hemp agriculture, where hemp fibres, hurds, and dust are produced.

For the gasoline production, the allocations were taken as currently implemented in the Ecoinvent database by its designers, using different methods for different parts of the product system. This shortcoming is less relevant when comparing different biofuel options. The partitioning factors-based economic values in the five studies are given in Table 3. In study (4) and (5) the authors also conducted sensitivity analysis on the price of shives and hurds. For the comparison in the present study, an average price of flax shives and the price of hemp hurds in the base case scenario are taken.

2.1.5. Impact Assessment. The categories selected for impact assessment in all five studies are as follows: (i) abiotic depletion potential (ADP),

(ii) global warming potential (GWP),

(iii) ozone layer depletion potential (ODP),

(iv) photochemical oxidation potential (POCP),

(v) human and ecotoxicity potential (HTP \& ETP),

(vi) acidification Potential (AP),

(vii) eutrophication Potential (EP).

The environmental impacts addressed here reflect the differences between operations of vehicles fuelled with gasoline, E10, E85, and pure ethanol. The results are normalized to the "world total" in order to compare the importance of each impact. Overall evaluation requires weighting, which has not been applied in this study. The Handbook on Life Cycle Assessment [55] states: "Weighting is an optional step for all non-comparative assertions; there is no best available method and there is no recommended set of weighting factors." Nevertheless, for actual decision making some sort of weighting always is required.

2.2. Results Comparison and Discussion. The LCA results of fuel ethanol from the five different feedstocks compared with gasoline for each impact category are presented in Figure 1. In order to compare the relative size of results in different impact categories, they are normalized to "world total 1995" and are all set to the same scale. This normalised score indicates the percentage the system would contribute to the world total score on that impact, for the reference year taken. 
2.2.1. Global Warming Potential (GWP). Global warming has always been considered as the most important category in biofuel LCA studies, a simple type of weighting. The results of GWP always draw special attention also due to the diversity of results between different studies. This stands also true in the present study. When sugarcane and switchgrass are the energy crops, ethanol fuels show better performance than gasoline. The reason for the decrease of GHG emissions is the large amount of $\mathrm{CO}_{2}$ taken up by the growth of sugarcane and switchgrass. Moreover, switchgrass seems to be a better feedstock than sugarcane because in the ethanol production from switchgrass, there is surplus electricity which is sold to the local grid. However in the sugarcaneethanol refinery, the cogenerated electricity is not enough to supply the refinery and additional electricity needs to be purchased from the grid. If the electricity supplied by the grid is also biobased in the future, its contribution to GHG emissions could be less.

However, when fuel ethanol is produced from corn stover, flax shives, and hemp hurds, the application of ethanol fuels leads to worse performance. Here the economic allocation applied in agriculture production in these three studies plays an important role. As compared to corn, flax, and hemp, the stover, shives, and hurds have much smaller partitioning factors due their low prices (see Table 3). Hence when economic allocation is applied, most of the $\mathrm{CO}_{2}$ uptakes in agriculture are allocated on corn, flax, and hemp fibres. Flax shives turned out to be the worst feedstock due to its smallest allocation factor (0.042). The substantial influence of allocation methods on the outcome of GWP is illustrated in Section 2.2.3.

2.2.2. Other Impact Categories. In the other six impact categories, the results of driving on fuel ethanol from different feedstocks are also diverse. The level of ADP is significantly reduced when replacing gasoline with fuel ethanol, irrespective of the feedstock used. Apparently this is due to the replacement of fossil resources by biomass. The levels differ among the five studies insignificantly. The reasons for these differences can be the energy efficiency in agriculture as well as in ethanol refinery. To have a better understanding in which subprocesses are energy intensive, a detailed energy analysis is required.

Normalized ODP shows substantially lower level than other impacts, which means that it contributes relatively less to the world total, negligible in comparison. Among all the ethanol fuels, sugarcane-derived ethanol is the best option regarding ODP. This indicates that less fossil energy is used in the life cycle of sugarcane-ethanol. This result is in accordance with the one of ADP, where ethanol from sugarcane also leads to the lowest impact. The ODP levels of fuel ethanol from other feedstocks do not differ significantly. Overall, the ODP score can be left out of account in decision making. Even a very high weight on this impact could not make it a relevant one.

Regarding POCP level, again sugarcane-derived ethanol shows the best performance, which is slightly lower than gasoline. POCP is mainly contributed by the emissions from production and refining of oil and gas, and the volatile organic compounds in the gasoline and ethanol life cycle, respectively. Thus when shifting gasoline to ethanol fuels, the emissions from fossil resource extraction are reduced; however, the emissions from ethanol production and transport of chemicals are increased. In all ethanol life cycles except the one derived from sugarcane, the level of increase is higher than the one of reduction. Among all switchgrass-derived ethanol is the worst option due the large amount of acetaldehyde emitted from ethanol fermentation, which contributes $77 \%$ to its total POCP score [31]. This finding indicates that, although the processes for ethanol product have all been optimized, possibilities for further optimization with better technology need to be investigated to reduce environmental impact.

In the category concerning HTP and ETP, ethanol fuels all have higher impact than gasoline. The main contributors of human and eco-toxicity are the production of chemicals and machineries used in agriculture. Among ethanol fuels from different feedstocks, ethanol from sugarcane and switchgrass perform worse. This does not mean that their agriculture processes are more polluting. The reason for this is again the partitioning factors based on economic allocation in the agriculture of corn stover, flax shives, and hemp hurds. Large amount of emissions in these three cases are allocated on the main crops-corn, flax, and hemp.

The levels of AP increase slightly in all cases except flax shives-derived ethanol when replacing gasoline with ethanol fuels. This level is mainly contributed by ammonia emitted in agriculture, nitrogen oxides $\left(\mathrm{NO}_{x}\right)$ emissions from operation of lorries and FFV, and sulphur dioxide $\left(\mathrm{SO}_{2}\right)$ from oil refinery. Hence in ethanol life cycles, although less $\mathrm{SO}_{2}$ is emitted from the oil refinery, ammonia emissions are not negligible. This results in worse performance of most of ethanol fuels. For the adverse results from shives-derived ethanol, the same reasoning as the one for HTP and ETP can be applied. As shives shares only a very small part of environmental burdens in agriculture, the level of AP is decreased.

With regards to EP the trend is similar to AP. The level of EP is mostly attributed to agriculture processes, especially the nitrate to ground water and nitrogen oxides $\left(\mathrm{NO}_{x}\right)$ to air from the application of nitrogen fertilizers. As flax shives has a much smaller allocation factor in agriculture than other feedstocks, it gives the best performance, followed by gasoline, and then stover, switchgrass and, sugarcane-derived ethanol. EP of hemp hurds-derived ethanol draws attention due to its significantly higher level compared to other fuel cycles. The main contributor of this is the large amount of nitrate leaching to fresh water.

In order to have a clear overview, the environmental performances per impact category from the best to the worse fuel option are summarized in Table 4.

It can be seen that different fuel options show better performance in different categories. The overall evaluation depends on the importance attached to each impact category. As weighting is not included in this study, it is impossible to draw conclusion on which fuel option is the best. However, as the results are normalized and are set to the same scale, it can 
TABLE 4: Overall results of environmental performance of all fuel options in all studies.

\begin{tabular}{lcccccc}
\hline \multirow{2}{*}{ Impact category } & \multicolumn{5}{c}{ Environmental performance } \\
\cline { 3 - 5 } & Best & & & & Worst \\
\hline GWP & Swi & Sug & Gas & Sto & Hur & Shi \\
GWP $\left(\mathrm{CO}_{2}\right.$-neutral) & Sug & Swi & Shi & Sto & Hur & Gas \\
ADP & Sug & Shi & Sto & Swi & Hur & Gas \\
ODP & Sug & Sto & Swi & Shi & Hur & Gas \\
POCP & Sug & Gas & Sto & Shi & Hur & Swi \\
HTP \& ETP & Gas & Shi & Hur & Sto & Swi & Sug \\
AP & Shi & Gas & Sug & Swi & Sto & Hur \\
EP & Shi & Gas & Sto & Swi & Sug & Hur \\
\hline
\end{tabular}

Gas: gasoline; Sto: stover-based ethanol; Sug: sugarcane-based ethanol; Swi: switchgrass-based ethanol; Shi: shives-based ethanol; Hur: hurds-based ethanol.

be seen that GWP, ADP, HTP, and ETP contribute relatively more to the world total; thus they deserve more attention when evaluating all the fuel options. POCP, AP, and EP are of less importance, and ODP definitely can be left out of account.

2.2.3. Influence of Methodology Choices. In the studies on stover, shives, and hurds-derived ethanol, sensitivity analyses on allocation methods were conduced. The results show that when allocations reflecting physically relationship (mass or energy content) are applied, GWP levels are significantly reduced. The reason for this outcome is that stover, shives, and hurds are agricultural coproducts which have low market prices when comparing to corn, flax, and hemp. When economic allocation is applied, most of the $\mathrm{CO}_{2}$ uptake is allocated to the crops due to their large partitioning factors; however, when mass or energy content-based allocation is applied, the amount of $\mathrm{CO}_{2}$ uptake allocated to stover, shives, and hurds increases due to the large amount produced. For toxic effects of pesticide use, economic allocation similarly leads to a very low share, and allocation by mass would increase the already high human and ecotoxicity scores substantially. This allocation dependency of outcomes has been explained in more details in three of the studies [12, $23,24]$. Therefore allocation issues are of crucial importance in LCA studies applied to biofuels and should be discussed explicitly whenever it is concerned.

In most of the studies the usual allocation procedure is followed dealing with $\mathrm{CO}_{2}$ uptake and $\mathrm{CO}_{2}$ emissions-the uptake counts as an extraction from atmosphere; hence the emissions of this biogenic $\mathrm{CO}_{2}$ at combustion are counted just the same as fossil-based $\mathrm{CO}_{2}$. In the field of LCA on biofuels, there also is a "CO${ }_{2}$-neutral" approach, which ignores both extractions and emissions of biogenic $\mathrm{CO}_{2}$. In a straightforward system that does not require allocation; the net result should be the same. However, when allocation is needed, this may no longer be the case. As the allocation methods applied strongly influence the results of GWP

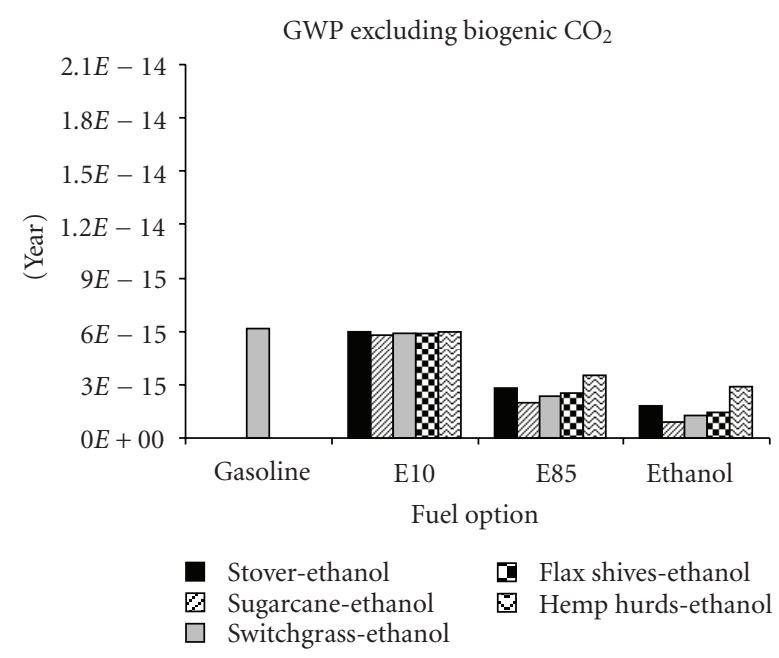

FIGURE 2: Results of GWP excluding biogenic $\mathrm{CO}_{2}$ in all studies.

scores, a comparative computation for the systems excluding biogenic $\mathrm{CO}_{2}$ was made, and the results are given in Figure 2.

When biogenic $\mathrm{CO}_{2}$ is excluded, reduction of GWP is achieved when replacing gasoline with ethanol fuels irrespective of the feedstocks used. As the switchgrassethanol system is relatively straightforward with only small amount of electricity cogenerated, its GWP levels do not differ significantly in both approaches (allocation versus $\mathrm{CO}_{2}$ neutral). For the other four studies, as economic allocation plays an important role, the results turn to be very different in the " $\mathrm{CO}_{2}$-neutral" approach. In fact, what has happened here by excluding biogenic $\mathrm{CO}_{2}$ is that $\mathrm{CO}_{2}$ escapes the selected allocation method. Instead, $\mathrm{CO}_{2}$ is allocated in all cases on the basis of carbon share of the products. Therefore, implicitly, another way of allocating is introduced in the carbon neutral approach and here then mixed with economic allocation.

The choice of allocation influences the impact category of global warming more significantly, as the other categories refer to more specific process in the chain and, more importantly, do not deal with negative emissions.

\section{Energy Considerations}

3.1. Methodology. The purpose of this section is to understand whether second-generation bioethanol is more energy efficient compared to the first-generation. We have conducted two energy analyses on bioethanol from corn stover [5] and sugarcane [40]. In both studies the energy inputs of all subprocesses are calculated and the resulting net energy values (NEVs) are compared with literature studies on firstgeneration bioethanol from corn and sugarcane and secondgeneration ethanol from switchgrass. In our sugarcaneethanol system, as the data used are from the same source as the ones in LCA study, two scenarios are considered: base case-ethanol and sugar are produced from the sugar extracted from cane, and bagasse is used for steam and electricity generation; future case-bagasse is also used for 
ethanol production, and heat and power are generated from the lignin residues and wastes.

All relevant processes in biomass production and ethanol conversion are included in the system boundaries as well as capital goods production and wastes management. No allocation is involved in the foreground processes, as all the energy used to produce all coproducts is taken into account. Two types of NEV are estimated-with and without accounting for coproduct energy values.

The outcomes of these two studies are compared with the six literature studies on corn-ethanol summarized by Farrell et al. [7, 9, 28-30, 56], one study on switchgrass-ethanol [9] and three studies on sugarcane ethanol $[28,36,57]$.

3.2. Results Comparison and Discussion. The net energy summaries excluding and including coproducts compared to the literature values are presented in Tables 5 and 6 , respectively.

When coproducts are not included meaning that all the inputs and outputs are $100 \%$ allocated to stover, three studies on corn-ethanol result in negative net energy values due to their then seemingly more intensive agriculture practice. The other three studies on corn ethanol yield very small positive NEV values compared to the ones of ethanol from sugarcane and cellulosic feedstocks (stover and switchgrass). However, stover is a relatively bad feedstock due to its intensive agriculture production process. The reason why the energy use in agriculture per litre of ethanol in stover-ethanol case is the highest is that the yield of ethanol from stover is lower than the one from corn. In order to produce 1 litre of ethanol more stover is needed - the average ethanol yield of ethanol from corn is $0.41 / \mathrm{kg}$, while from stover it is only $0.31 / \mathrm{kg}$.

When the energy credits (taken as the energy content of the product) are taken into account for all coproducts, all studies yield positive net energy values. The highest NEV of stover-ethanol attributes to the co-product in agriculture-corn. The resulting NEVs from corn-ethanol studies become comparable with those from ethanol derived from switchgrass and sugarcane. In the study conducted by Hadzhiyska et al. [32] sugar is coproduced in the ethanol refinery in both base and future case; the values of net energy are significantly higher than the ones from other studies without sugar coproduction. This indicates that outcomes of net energy calculations depend on whether or not taking the energy values of coproducts into account.

As mentioned earlier, in our sugarcane-ethanol study, the base case demonstrates the current practice in Brazilian ethanol industries-ethanol and sugar are produced from sugar juice after cane milling, and steam and electricity are generated from combustion of bagasse; the future case presents the option that bagasse is also utilized for ethanol production, while heat and power are only generated from the lignin residues and wastes. In the base case $2.6 \mathrm{MJ} /$ litre of surplus electricity is generated and sold to the grid; however, in the future case extra electricity needs to be purchased from the grid to supply the refinery. The results in Table 6 show that from an energy conservation perspective, it is better to use bagasse for electricity generation instead of ethanol production in such a refinery.

\section{Conclusions and Recommendations}

In the first part of this paper five studies on LCA of ethanol from lignocellulosic feedstocks are summarized. Seven impact categories are used for assessment and the results from different studies are compared per category. One interesting outcome is that ODP scores are quantitatively irrelevant in all cases, even if attributing a very high weight to this impact category. One limitation of the current method for life cycle impact assessment is that it does not reckon with the contribution of $\mathrm{N}_{2} \mathrm{O}$ emissions to ODP, as recent findings show that $\mathrm{N}_{2} \mathrm{O}$ now has become the major cause of depletion of ozone layer [58].

In terms of GWP when economic allocation is applied, switchgrass is the best energy crop, followed by sugarcane. In both cases significant reductions of GHG emissions are achieved, which attributes to the $\mathrm{CO}_{2}$ uptake in agriculture. The electricity surplus generated in switchgrass-ethanol refinery also helps reduce the GHG emissions in the life cycle of ethanol fuels. The application of ethanol fuels from stover, shives, and hurds leads to worse performance than gasoline, due to the small partitioning factors based on economic allocation in agriculture. When the " $\mathrm{CO}_{2}$-netural" approach is applied, reduction of GHG emissions is achieved by ethanol fuels from all feedstocks, compared to gasoline. Sugarcane, in this approach, becomes the most favourable feedstock, followed by switchgrass.

Sugarcane-derived ethanol turns out to be the best option in terms of ADP, ODP, and POCP. Its less energy intensive agriculture and ethanol process lead to less fossil resource extraction and related emissions which contributes POCP significantly. Ethanol derived from corn stover and flax shives shows modest performance, and hemp hurds and switchgrass are unfavourable feedstocks in these three categories.

In the category of HTP and ETP and AP and EP, flax shives-derived ethanol shows the best environmental performance among all the ethanol fuels. As the agriculture practices, especially the production machineries and application of fertilizers, contribute most to these impact, flax shives, sharing only small part of environmental burdens due to its small allocation factor (0.042), becomes the most promising feedstock.

In most of the categories hemp hurds-derived ethanol shows the worst performance due to its intensive agriculture practice. Thus this feedstock is not recommended for ethanol production, which may then be utilized directly for heat and power generation, unless its agriculture process can be significantly improved.

In many impact categories (GWP, POCP, HTP \& ETP, AP and EP) ethanol fuels as a whole do not show advantages over gasoline, which means that strong promotion of bioethanol as a transport fuel needs to be carefully considered. More advanced technologies with optimization of energy use and emissions in both agriculture and ethanol refinery still need to be developed to reduce the current relatively high scores.

It is worth noting that in the sugarcane-ethanol study, ethanol is converted from both sugar and bagasse, as it is 
TABLE 5: Net energy summary excluding coproducts, no allocation.

\begin{tabular}{|c|c|c|c|c|c|c|c|}
\hline \multirow{2}{*}{ Feedctock } & & \multicolumn{6}{|c|}{ Energy use $\left(\mathrm{MJ} / \mathrm{L}^{\mathrm{a}}\right)$} \\
\hline & & Agriculture & Biorefinery & Total input & Ethanol $^{\mathrm{b}}$ & Total output & Net energy value (NEV) \\
\hline Stover & Luo et al. [5] & 10.0 & 0.5 & 10.5 & 21.2 & 21.2 & 10.7 \\
\hline \multirow{6}{*}{ Corn } & Patzek [56] & 9.9 & 17.0 & 26.9 & 21.2 & 21.2 & -5.7 \\
\hline & $\begin{array}{l}\text { Pimentel and } \\
\text { Patzek [7] }\end{array}$ & 10.0 & 17.0 & 27.0 & 21.2 & 21.2 & -5.8 \\
\hline & $\begin{array}{l}\text { Shapouri and } \\
\text { McAloon [30] }\end{array}$ & 5.3 & 15.2 & 20.5 & 21.2 & 21.2 & 0.7 \\
\hline & Graboski [29] & 5.6 & 16.6 & 22.2 & 21.2 & 21.2 & -1.0 \\
\hline & $\begin{array}{l}\text { Dias de Oliveira } \\
\text { et al. }[28]\end{array}$ & 6.3 & 14.1 & 20.4 & 21.2 & 21.2 & 0.8 \\
\hline & Wu et al. [9] & 6.6 & 12.5 & 19.1 & 21.2 & 21.2 & 2.1 \\
\hline Switchgrass & Wu et al. [9] & 2.4 & 1.0 & 3.4 & 21.2 & 21.2 & 17.8 \\
\hline \multirow{5}{*}{ Sugarcane } & $\begin{array}{l}\text { Hadzhiyska } \\
\text { et al. (base case) } \\
{[32]}\end{array}$ & 6.5 & 0.1 & 6.6 & 21.2 & 21.2 & 14.6 \\
\hline & $\begin{array}{l}\text { Hadzhiyska } \\
\text { et al. (future } \\
\text { case) [32] }\end{array}$ & 2.7 & 0.5 & 3.2 & 21.2 & 21.2 & 18.0 \\
\hline & $\begin{array}{l}\text { Pimentel and } \\
\text { Patzek [57] }\end{array}$ & 2.6 & 3.4 & 6.0 & 21.2 & 21.2 & 15.2 \\
\hline & $\begin{array}{l}\text { Diaz de Oliveira } \\
\text { et al. [28] }\end{array}$ & 5.6 & 0.6 & 6.2 & 21.2 & 21.2 & 15.0 \\
\hline & $\begin{array}{l}\text { Macedo et al. } \\
{[36]}\end{array}$ & 2.0 & 0.3 & 2.3 & 21.2 & 21.2 & 18.9 \\
\hline
\end{tabular}

${ }^{a}$ The unit of energy use is MJ per litre of ethanol produced from biorefinery. ${ }^{b}$ Normalized energy value for ethanol based on lower heating value (LHV).

proposed to be the common practice in the future in Brazil. In the future research, in order to know whether bagasse is a promising lignocellulosic feedstock, environmental performance of ethanol fuels from bagasse shall be studied.

The choice of allocation methodology is essential for the outcomes especially related to GHG emissions. As this is an important issue and one of the main reasons for considering biofuels as a replacement of fossil fuels, it should be given special attention in life cycle-based studies of biofuels. In order to support decision making, sensitivity analysis shall always be conducted whenever more than one allocation methods can be applied. Furthermore, the results from the " $\mathrm{CO}_{2}$-neutral" approach seem to be more realistic, as GWP levels are highly affected by the allocation methods applied. It is important that LCA practitioners realize this and deal with it in an appropriate manner.

Although the LCA results from only five studies are compared, these five feedstocks can, to certain extent, represent other lignocelluloses. This paper gives an indication on the environmental performance of second-generation bioethanol as a whole in comparison with gasoline; hence it contributes significantly to the current debate on the importance of biofuels in future energy mix.

LCA methodology as its stands cannot capture all the relevant environmental impacts. Direct and indirect land use and competition with food products do not fit well into the LCA framework. A broader approach to expand LCA studies to include these impacts is required in future research.
The second part of this paper summarizes the NEV results from ethanol from stover and sugarcane and compares them with literature values. Two approaches are considered-excluding and including co-product energy credits. This is in fact similar to the allocation issue which has been extensively discussed in the stover-ethanol study [12]. In order to prevent applying allocation procedure, here "including co-product credits" is similar to the "system expansion" approach LCA studies while "excluding coproduct credits" means "cut-off of coproducts/wastes".

When coproducts are not included, three studies on corn-ethanol result in a negative NEV. The others result in positive values with different degrees. Sugarcane and lignocellulosic feedstocks are more favourable due to their less energy intensive agriculture practice and refining process. The low-energy inputs in these ethanol refining processes are due to the steam and electricity cogeneration inside refineries. This suggests that cogeneration of heat and power from process wastes is an important way to increase energy efficiency in the cellulosic ethanol process.

When the energy credits of all coproducts are taken into account, all studies yield positive net energy values with the highest from stover-ethanol case. Accounting for the energy values of coproducts especially corn, stover, and sugar produced in different cases affects strongly the performance of most cases from an energy perspective. This issue of coproduct credits is in fact similar to the allocation issue in LCA studies but is only solved here in a different manner. 
TABLE 6: Net energy summary including coproducts, no allocation.

\begin{tabular}{|c|c|c|c|c|c|c|c|c|c|}
\hline \multirow{2}{*}{ Feedstock } & & \multicolumn{8}{|c|}{ Energy use $\left(\mathrm{MJ} / \mathrm{L}^{\mathrm{a}}\right)$} \\
\hline & & Agriculture & Biorefinery & Total input & Ethanol $^{\mathrm{b}}$ & $\begin{array}{l}\text { Coproducts } \\
\text { in } \\
\text { agriculture }^{\mathrm{c}}\end{array}$ & $\begin{array}{l}\text { Coproducts in } \\
\text { bioreinery }^{\mathrm{d}}\end{array}$ & Total output & $\begin{array}{c}\text { Net energy } \\
\text { value }(\mathrm{NEV})\end{array}$ \\
\hline Stover & Luo et al. [5] & 10.0 & 0.5 & 10.5 & 21.2 & 85.2 & 0.2 & 106.6 & 96.1 \\
\hline \multirow{6}{*}{ Corn } & Patzek [56] & 9.9 & 17.0 & 26.9 & 21.2 & 25.9 & 4.1 & 51.2 & 24.3 \\
\hline & $\begin{array}{l}\text { Pimentel and } \\
\text { Patzek [7] }\end{array}$ & 10.0 & 17.0 & 27.0 & 21.2 & 25.9 & 1.9 & 49.0 & 22.0 \\
\hline & $\begin{array}{l}\text { Shapouri and } \\
\text { McAloon [30] }\end{array}$ & 5.3 & 15.2 & 20.5 & 21.2 & 24.0 & 7.3 & 52.5 & 32.0 \\
\hline & Graboski [29] & 5.6 & 16.6 & 22.2 & 21.2 & 24.6 & 4.1 & 49.9 & 27.7 \\
\hline & $\begin{array}{l}\text { Diaz de Oliveira } \\
\text { et al. [28] }\end{array}$ & 6.3 & 14.1 & 20.4 & 21.2 & 24.6 & 4.1 & 49.9 & 29.5 \\
\hline & Wu et al. [9] & 6.6 & 12.5 & 19.1 & 21.2 & 24.6 & 4.0 & 49.8 & 30.7 \\
\hline Switchgrass & Wu et al. [9] & 2.4 & 1.0 & 3.4 & 21.2 & 0.0 & 4.8 & 26.0 & 22.6 \\
\hline \multirow{5}{*}{ Sugarcane } & $\begin{array}{l}\text { Hadzhiyska } \\
\text { et al. (base case) } \\
{[32]}\end{array}$ & 6.5 & 0.1 & 6.6 & 21.2 & 0.0 & 32.7 & 53.9 & 47.3 \\
\hline & $\begin{array}{l}\text { Hadzhiyska et } \\
\text { al. (future case) } \\
{[32]}\end{array}$ & 2.7 & 0.5 & 3.2 & 21.2 & 0.0 & 12.6 & 33.8 & 30.6 \\
\hline & $\begin{array}{l}\text { Pimentel and } \\
\text { Patzek [57] }\end{array}$ & 2.6 & 3.4 & 6.0 & 21.2 & 0.0 & 0.0 & 21.2 & 15.2 \\
\hline & $\begin{array}{l}\text { Diaz de Oliveira } \\
\text { et al. [28] }\end{array}$ & 5.6 & 0.6 & 6.2 & 21.2 & 0.0 & 1.1 & 22.3 & 16.1 \\
\hline & $\begin{array}{l}\text { Macedo et al. } \\
\text { [36] }\end{array}$ & 2.0 & 0.3 & 2.3 & 21.2 & 0.0 & 3.0 & 24.2 & 21.9 \\
\hline
\end{tabular}

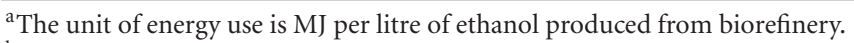

${ }^{b}$ Normalized energy value for ethanol based on lower heating value (LHV).

${ }^{c}$ In stover-ethanol study it refers to the corn as a coproduct in the agriculture; in the other six studies on corn-ethanol it refers to the harvested stover (60\%, dry mass basis) as a coproduct, and the values are estimated in this study.

${ }^{\mathrm{d}}$ In stover-ethanol and switchgrass-ethanol study it refers to electricity; in corn-ethanol studies it refers to a range of products from corn milling, such as dried distiller grains, corn gluten feed, and corn oil; in sugarcane-ethanol study it refers to electricity surplus or/and bagasse.

The results of the sugarcane-ethanol cases conducted by us show that it is better to use bagasse for electricity generation instead of ethanol production in such a refinery. Here we assume the "grid" as the average electricity mix from Ecoinvent database. If the electricity supplied by the grid can be produced fully from renewable sources in the future, the outcomes would be different.

The changes occurred after taking all coproducts into account are striking in the case of ethanol derived from corn, stover, and sugarcane [32] due to the large amount of stover (not using corn), corn (not using stover), and sugar coproduced. Literature studies on energy assessment are not conducted in a consistent way when co-product energy credits are concerned. For instance, Pimentel and Patzek in $[7,56,57]$ conclude negative NEV without accounting for the energy value of the coproducts which can be produced from the ethanol life cycle. Farrell et al. [6] reckon with the coproducts from corn-ethanol biorefinery for these studies, but not the stover produced from agriculture. Our study shows the importance and urgency of developing a consistent and relevant methodology for energy analysis in biofuel research.
As we account for total energy inputs and outputs, which means that no allocation method is applied, taking all coproducts into account becomes essential. To assess the energy flow of only one main product, an allocation based on energy content may be applied in some cases, that is, between corn and stover, and between ethanol and electricity. Nevertheless, for the combined production of ethanol and sugar, it is difficult as the energy values of sugar and ethanol do not belong to the same category (food versus energy product).

Although we compare studies on only four feedstocks, they are representative in the debate on energy analysis of first- and second-generation bioethanol. Irrespective of the methodology used, switchgrass and sugarcane seem to be good feedstocks for ethanol production due to their lowenergy use in agricultural production and good environmental performance.

\section{Acknowledgment}

This project is financially supported by The Netherlands Ministry of Economic Affairs and the B-Basic partner organi- 
zations (http://www.b-basic.nl/) through B-Basic, a publicprivate NWO-ACTS program (ACTS: Advanced Chemical Technologies for Sustainability).

\section{References}

[1] "Renewable Energy Road Map-Renewable energies in the 21 st century," building a more sustainable future. 2007. COM, 848 final, 2006.

[2] "Directive 2009/28/EC of the European Parliament and of the Council," 2009.

[3] DOE/EIA-0383, Annual Energy Outlook 2008 with Projections to 2030, U.S. Energy Information Administration, Washington, DC, USA, 2008.

[4] A. Lavigne and S. E. Powers, "Evaluating fuel ethanol feedstocks from energy policy perspectives: a comparative energy assessment of corn and corn stover," Energy Policy, vol. 35, no. 11, pp. 5918-5930, 2007.

[5] L. Luo, E. van der Voet, and G. Huppes, "An energy analysis of ethanol from cellulosic feedstock-Corn stover," Renewable and Sustainable Energy Reviews, vol. 13, no. 8, pp. 2003-2011, 2009.

[6] A. E. Farrell, R. J. Plevin, B. T. Turner, A. D. Jones, M. O'Hare, and D. M. Kammen, "Ethanol can contribute to energy and environmental goals," Science, vol. 311, no. 5760, pp. 506-508, 2006.

[7] D. Pimentel and T. W. Patzek, "Ethanol production using corn, switchgrass, and wood; biodiesel production using soybean and sunflower," Natural Resources Research, vol. 14, no. 1, pp. 65-76, 2005.

[8] M. Wang, "Developing and use of GREET 1.6 fuel-cycle model for transportation fuels and vehicle technologies," Tech. Rep. ANL/ESD/TM-163, Argonne National Laboratory, Argonne, Ill, USA, 2001.

[9] M. Wu, Y. Wu, and M. Wang, "Energy and emission benefits of alternative transportation liquid fuels derived from switchgrass: a fuel life cycle assessment," Biotechnology Progress, vol. 22, no. 4, pp. 1012-1024, 2006.

[10] C. A. Cardona Alzate and O. J. Sánchez Toro, "Energy consumption analysis of integrated flowsheets for production of fuel ethanol from lignocellulosic biomass," Energy, vol. 31, no. 13, pp. 2447-2459, 2006.

[11] S. Kim, B. E. Dale, and R. Jenkins, "Life cycle assessment of corn grain and corn stover in the United States," International Journal of Life Cycle Assessment, vol. 14, no. 2, pp. 160-174, 2009.

[12] L. Luo, E. van der Voet, G. Huppes, and H. A. Udo de Haes, "Allocation issues in LCA methodology: a case study of corn stover-based fuel ethanol," International Journal of Life Cycle Assessment, vol. 14, no. 6, pp. 529-539, 2009.

[13] E. Searcy and P. C. Flynn, "Processing of straw/corn stover: comparison of life cycle emissions," International Journal of Green Energy, vol. 5, no. 6, pp. 423-437, 2008.

[14] J. Sheehan, A. Aden, K. Paustian, et al., "Energy and environmental aspects of using corn stover for fuel ethanol," Journal of Industrial Ecology, vol. 7, no. 3-4, pp. 117-146, 2004.

[15] S. Spatari, Y. Zhang, and H. L. Maclean, "Life cycle assessment of switchgrass- and corn stover-derived ethanol-fueled automobiles," Environmental Science and Technology, vol. 39, no. 24, pp. 9750-9758, 2005.

[16] D. Styles and M. B. Jones, "Life-cycle environmental and economic impacts of energy-crop fuel-chains: an integrated assessment of potential GHG avoidance in Ireland," Environmental Science and Policy, vol. 11, no. 4, pp. 294-306, 2008.

[17] T. Botha and H. von Blottnitz, "A comparison of the environmental benefits of bagasse-derived electricity and fuel ethanol on a life-cycle basis," Energy Policy, vol. 34, no. 17, pp. 26542661, 2006.

[18] L. Luo, E. van der Voet, and G. Huppes, "Life cycle assessment and life cycle costing of bioethanol from sugarcane in Brazil," Renewable and Sustainable Energy Reviews, vol. 13, no. 6-7, pp. 1613-1619, 2009.

[19] B. Gabrielle and N. Gagnaire, "Life-cycle assessment of straw use in bio-ethanol production: a case study based on biophysical modelling," Biomass and Bioenergy, vol. 32, no. 5, pp. 431-441, 2008.

[20] T. Beer and T. Grant, "Life-cycle analysis of emissions from fuel ethanol and blends in Australian heavy and light vehicles," Journal of Cleaner Production, vol. 15, no. 8-9, pp. 833-837, 2007.

[21] G. Z. Fu, A. W. Chan, and D. E. Minns, "Life cycle assessment of bio-ethanol derived from cellulose," International Journal of Life Cycle Assessment, vol. 8, no. 3, pp. 137-141, 2003.

[22] A. J. Kemppainen and D. R. Shonnard, "Comparative life-cycle assessments for biomass-to-ethanol production from different regional feedstocks," Biotechnology Progress, vol. 21, no. 4, pp. 1075-1084, 2005.

[23] S. González García, L. Luo, M. T. Moreira, G. Feijoo, and G. Huppes, "Life cycle assessment of flax shives derived second generation ethanol fueled automobiles in Spain," Renewable and Sustainable Energy Reviews, vol. 13, no. 8, pp. 1922-1933, 2009.

[24] S. González García, L. Luo, M. T. Moreira, G. Feijoo, and G. Huppes, "Fuel ethanol from hemp hurds: environmental performance," submitted.

[25] J. Sheehan, A. Aden, and C. Riley, "Is ethanol from corn stover sustainable? Adventures in cyber-farming: a life cycle assessment of the production of ethanol from corn stover for use in a flex fuel vehicle," Draft Report for Peer Review, NREL, Golden, Colo, USA, 2002.

[26] S. Kim and B. E. Dale, "Allocation procedure in ethanol production system from corn grain: I. System expansion," International Journal of Life Cycle Assessment, vol. 7, no. 4, pp. 237-243, 2002.

[27] J. Malça and F. Freire, "Renewability and life-cycle energy efficiency of bioethanol and bio-ethyl tertiary butyl ether (bioETBE): assessing the implications of allocation," Energy, vol. 31, no. 15, pp. 3362-3380, 2006.

[28] M. E. Dias de Oliveira, B. E. Vaughan, and E. J. Rykiel Jr., "Ethanol as fuel: energy, carbon dioxide balances, and ecological footprint," BioScience, vol. 55, no. 7, pp. 593-602, 2005.

[29] M. Graboski, Fossil Energy Use in the Manufacture of Corn Ethanol, National Corn Growers Association, Washington, DC, USA, 2002.

[30] H. Shapouri and A. McAloon, The 2001 Net Energy Balance of Corn-Ethanol, U.S. Department of Agriculture, Washington, DC, USA, 2002.

[31] Y. Bai, L. Luo, and E. van der Voet, "Life cycle assessment of switchgrass-derived ethanol as transport fuel," International Journal of Life Cycle Assessment, vol. 15, pp. 468-477, 2010.

[32] D. Hadzhiyska, L. Luo, and E. van der Voet, "An energy analysis of ethanol from sugar cane," CML Report, Leiden, The Netherlands, 2009. 
[33] "Swiss Centre of Life Cycle Inventories," June 2007, http: //www.ecoinvent.org/.

[34] "Chain Management by Life Cycle Assessment (CMLCA)," May 2007, http://cml.leiden.edu/software/software-cmlca .html.

[35] “U.S. Life-Cycle Inventory Database," June 2007, http://www .nrel.gov/lci/.

[36] I. C. Macedo, M. R. L. V. Leal, and J. E. A. R. da Silva, "Assessment of greenhouse gas emissions in the production and use of fuel ethanol in Brazil," Report, Government of the State of São Paulo and Secretariat of the Environment, São Paulo, Brazil, 2004.

[37] M. Bullard and P. Metcalfe, "Estimating the energy requirement and $\mathrm{CO}_{2}$ emissions from production of the perennial grasses miscanthus, switchgrass and reed canary grass," Tech. Rep. ETSU B/U1/00645/REP.

[38] T. Nemecek and T. Kägi, "Life cycle inventories of Swiss and European agricultural production systems," Ecoinvent Report 15, Swiss Centre for Life Cycle Inventories, Dübendorf, Switzerland, 2007.

[39] T. Nemecek, A. Heil, O. Huguenin, et al., "Life cycle inventories of agricultural production systems," Ecoinvent Report 15, Swiss Centre for Life Cycle Inventories, Dübendorf, Switzerland, 2004.

[40] M. Z. Hauschild, "Estimating pesticide emissions for LCA of agricultural products," in Agricultural Data for Life Cycle Assessments, B. P. Weidema and M. J. G. Meeusen, Eds., vol. 2, pp. 64-79, LCANet Food, The Hague, The Netherlands, 2000.

[41] E. Audsley, S. Alber, R. Clift, et al., "Harmonization of environmental life cycle assessment for agriculture," Concerted Action AIR3-CT94-2028, European Commission. DG VI Agriculture. SRI, Silsoe, UK, 1997.

[42] D. Arrouays, J. Balesdent, J. C. Germon, P. A. Jayet, J.F. Soussana, and P. Stengel, "Contribution à la lutte contre l'effet de serre. Stocker du carbone dans les sols agricoles de France? Expertise scientifique collective," Rapport d'expertise réalisé par INRA à la demande du Ministère de l'Ecologie et du Développement Durable, INRA, Paris, France, 2002.

[43] EMEP/CORINAIR, "Atmospheric emission inventory guidebook," Tech. Rep. 11, European Environment Agency, Copenhagen, Denmark, 2006.

[44] M. Spielmann, T. Kägi, P. Stadler, and O. Tietje, "Life cycle inventories of transport services," Ecoinvent Report 14, Swiss Centre for Life Cycle Inventories, Dübendorf, Switzerland, 2004.

[45] A. Aden, M. Ruth, and K. Ibsen, "Lignocellulosic biomass to ethanol process design and economics utilizing co-current dilute acid prehydrolysis and enzymatic hydrolysis for corn stover," Tech. Rep. NREL/TP-510-32438, 2002.

[46] Ç. Efe, A. J. J. Straathof, and L. A. M. van der Wielen, "Technical and economical feasibility of production of ethanol from sugarcane and sugarcane bagasse," in B-Basic Internal Report, 2005.

[47] O. Guerra Miguez, D. Siva Siddarthan, and D. A. Suárez Zuluaga, "Technical and economical feasibility of production of ethanol from switchgrass," in B-Basic Internal Report, Delft University of Technology, Delft, The Netherlands, 2009.

[48] A. Tukker, G. Huppes, J. B. Guinée, et al., "Environmental Impact of Products (EIPRO)-Analysis of the life cycle environmental impacts related to the final consumption of the EU-25," 2005.

[49] K. J. Kelly, B. K. Bailey, T. C. Coburn, W. Clark, and P. Lissiuk, "Federal test procedure emissions test results from ethanol variable-fuel vehicle Chevrolet Luminas," in Society for Automotive Engineers, International Spring Fuels and Lubricants Meeting, Dearborn, Mich, USA, 1996.

[50] A. H. Reading, J. O. W. Norris, E. A. Feest, and E. L. Payne, "Ethanol emissions testing," AEAT unclassified E\&E/DDSE/02/021, Issue 3, 2002.

[51] ISO Norm 14040, "Life cycle assessment: principles and framework," Environmental management, 2006.

[52] ISO Norm 14044, "Life cycle assessment: requirement and guidelines," Environmental management, 2006.

[53] G. Huppes, Macro-Environmental Policy: Principles and Design, Elsevier, Amsterdam, The Netherlands, 1993.

[54] J. B. Guinée, R. Heijungs, and G. Huppes, "Economic allocation: examples and derived decision tree," International Journal of Life Cycle Assessment, vol. 9, no. 1, pp. 23-33, 2004.

[55] J. B. Guinée, Ed., Handbook on Life Cycle AssessmentOperational Guide to the ISO Standard, Kluwer Academic Publishers, Dodrecht, The Netherlands, 2002.

[56] T. W. Patzek, "Thermodynamics of the corn-ethanol biofuel cycle," Critical Reviews in Plant Sciences, vol. 23, no. 6, pp. 519567,2004

[57] D. Pimentel and T. Patzek, "Ethanol production: energy and economic issues related to U.S. and Brazilian sugarcane," Natural Resources Research, vol. 16, no. 3, pp. 235-242, 2007.

[58] A. R. Ravishankara, J. S. Daniel, and R. W. Portmann, "Nitrous oxide $\left(\mathrm{N}_{2} \mathrm{O}\right)$ : the dominant ozone-depleting substance emitted in the 21 st century," Science, vol. 326, no. 5949, pp. 123125,2009 . 

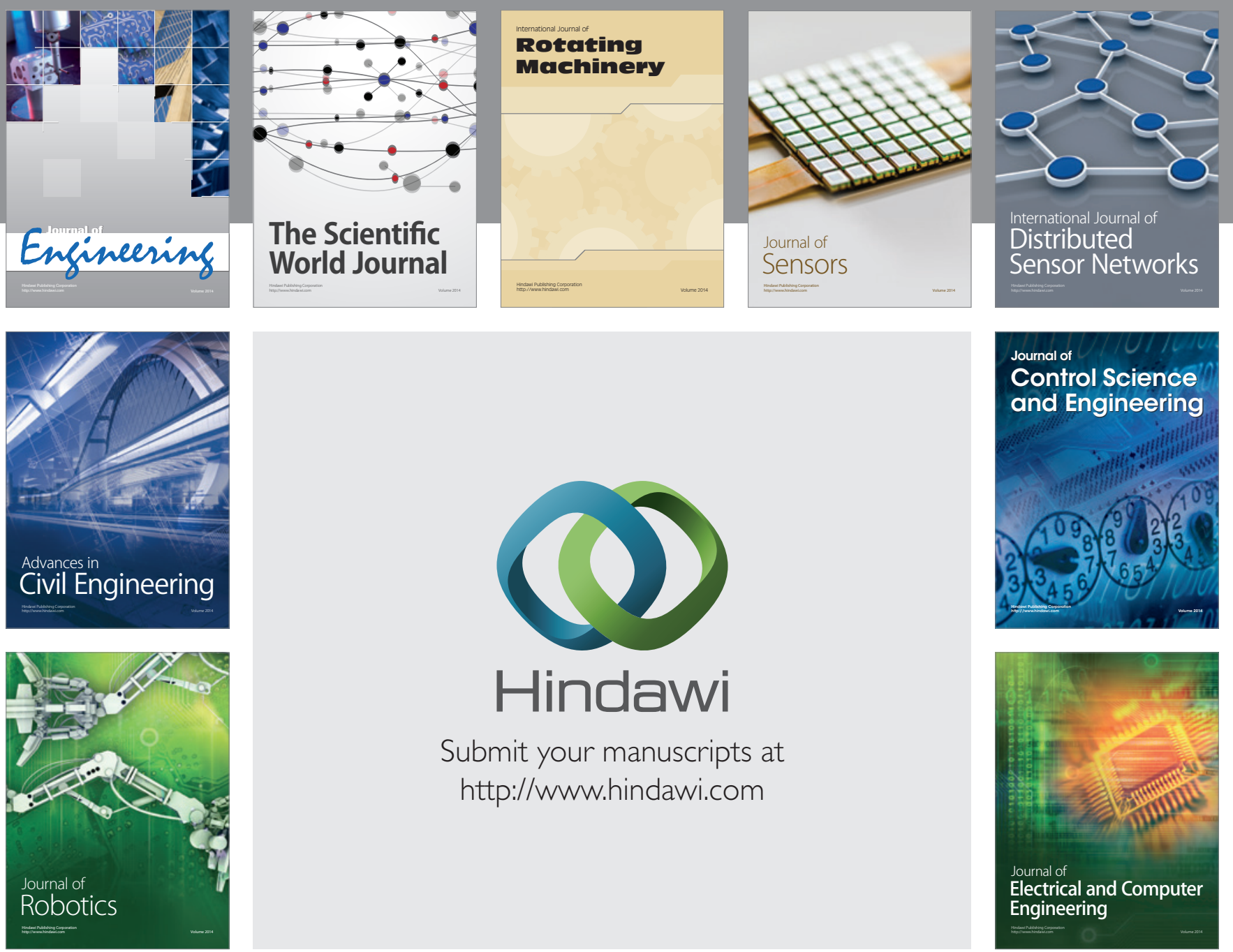

Submit your manuscripts at

http://www.hindawi.com
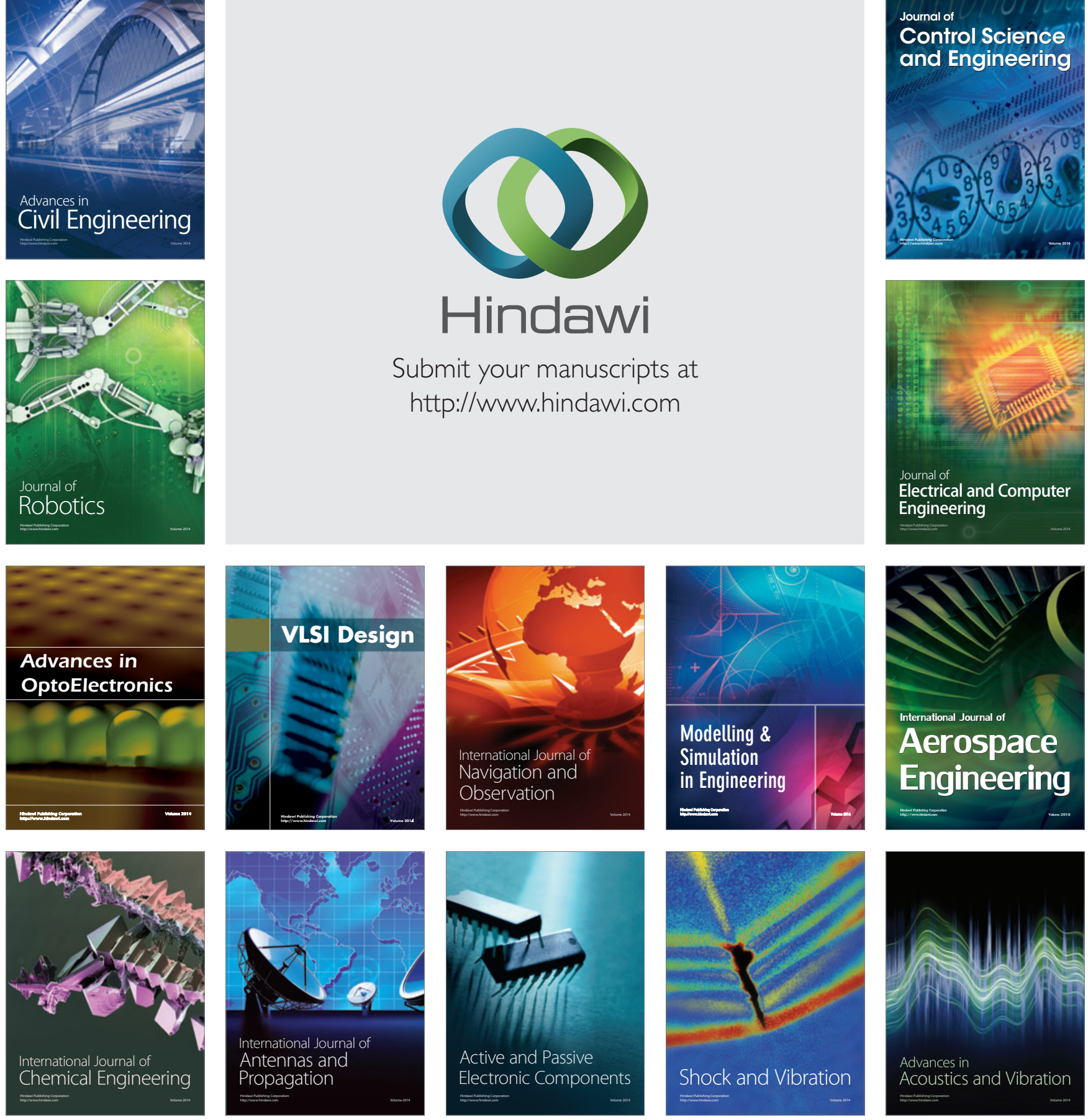